Check for updates

Cite this: RSC Adv., 2017, 7, 32427

Received 2nd May 2017

Accepted 9th June 2017

DOI: 10.1039/c7ra04950a

rsc.li/rsc-advances

\section{Catalytic activity comparison of Zr-SBA-15 immobilized by a Brønsted-Lewis acidic ionic liquid in different esterifications}

\author{
Liming Dai, Qian Zhao, Minglan Fang, Ruifeng Liu, Mingfeng Dong \\ and Tingshun Jiang (D)*
}

\begin{abstract}
Zirconium-incorporated SBA-15 mesoporous molecular sieves (Zr-SBA-15) with different Si/Zr molar ratios were one-pot synthesized and characterized by XRD, TEM and $\mathrm{N}_{2}$ physical adsorption. The Brønsted-Lewis acidic ionic liquid 1-(3-sulfonic acid)-propy l-3-methylimidazole chlorozincinate ([mim-ps] $\mathrm{Cl}-\mathrm{ZnCl}_{2}$ ) was prepared by a hydrothermal process and its acidity was measured by FT-IR spectroscopy using acetonitrile and pyridine as probes. The $\mathrm{Zr}-\mathrm{SBA}-15$ catalyst immobilized by $[\mathrm{mim}-\mathrm{ps}] \mathrm{Cl}-\mathrm{ZnCl} 2(\mathrm{Zr}-\mathrm{SBA}-$ 15/[mim-ps] $\mathrm{Cl}-\mathrm{ZnCl}_{2}$ ) was prepared by a wet impregnation method and characterized by XRD, BET, FTIR spectroscopy, TEM, XPS and TG. In particular, the catalytic activities of Zr-SBA-15 and Zr-SBA-15/ [mim-ps] Cl- $\mathrm{ZnCl}_{2}$ in the esterification of acetic acid were evaluated with $n$-butyl alcohol $(n-\mathrm{BuOH})$, benzyl alcohol $(\mathrm{BnOH})$ and cyclohexanol ( $\mathrm{Naxol})$. The results show that $\mathrm{Zr}-\mathrm{SBA}-15 /[\mathrm{mim}-\mathrm{ps}] \mathrm{Cl}-\mathrm{ZnCl}_{2}$ exhibited enhanced catalytic properties compared to $\mathrm{Zr}-\mathrm{SBA}-15$. Under optimal conditions, the acetic acid conversion over $\mathrm{Zr}-\mathrm{SBA}-15 /[\mathrm{mim}-\mathrm{ps}] \mathrm{Cl}-\mathrm{ZnCl}_{2}$ reached 89.7, 93.6, and 84.9\% for $n-\mathrm{BuOH}, \mathrm{BnOH}$ and Naxol, respectively. After 5 cycles, the acetic acid conversion decreased slightly. Zr-SBA-15/[mim$\mathrm{ps}] \mathrm{Cl}-\mathrm{ZnCl}_{2}$ was found to be an outstanding catalyst for esterification.
\end{abstract}

\section{Introduction}

Organic esters are an important class of intermediate species, commonly used in fine chemicals, perfumes, medicines, surfactants, and cosmetics. With the recent increase in consumption, there is a great demand for organic esters. ${ }^{1}$ In order to reduce the reaction temperature and reaction time, strong acid catalysts are usually added to accelerate the process. However, due to their disadvantages such as having difficult separations, being hard to reuse and causing the corrosion of reactors and pollution, traditional catalysts such as homogeneous acid catalysts (e.g. sulfuric acid, $p$-TSA, etc.) are not entirely satisfactory..$^{2-4}$ Besides, some strong solid acid catalysts like Nafion resin catalysts show high catalytic activity for esterification. Nevertheless, they are known to suffer great deactivation easily. ${ }^{5,6}$ Therefore, an efficient and environment-friendly catalyst is necessary.

Ionic liquids have been proved to be very useful and environmentally friendly catalysts due to their low vapor pressure and non-flammable nature. ${ }^{7,8}$ On the other hand, ionic liquids, which are completely composed of ions, can be designed to possess a definite set of properties. In this manner some acidic groups like chloride or sulfonic alkyl groups can be introduced into ionic liquids. ${ }^{9,10}$ For example, Qiao et al. applied a chlorine-

School of Chemistry and Chemical Engineering, Jiangsu University, 301 Xuefu Road, Zhenjiang 212013, Jiangsu, P. R. China. E-mail: tshjiang@ujs.edu.cn; Fax: +860511-88791800; Tel: +86-0511-88791800 aluminate acidic ionic liquid modified by $\mathrm{HCl}$ as a catalyst for alkylations of benzene and found that this ionic liquid had better catalytic activity in comparison with an anhydrous aluminium chloride catalyst. ${ }^{11}$ Lunagariya et al. used a sulfonic acid group functionalized ionic liquid catalyst for the esterification of $n$-butanol with acetic acid and obtained a high conversion. ${ }^{12}$ Recently, a class of acidic ionic liquids with both Lewis and Brønsted acid sites has received much attention, for it combined the advantages of Lewis and Brønsted acid sites. ${ }^{13-16}$ As we all know, both Lewis and Brønsted acids can accelerate the process of esterification. For example, Deng et al. reported that the room temperature ionic liquid 1-butylpyridinium chloride-aluminium(III) chloride was a good catalyst for various esterifications, enabling high conversion and selectivity. ${ }^{17}$ Gui et al. used three Brønsted acidic ionic liquids as catalysts for the esterification of carboxylic acids and obtained good carboxylic acid conversion and high selectivity. ${ }^{18}$ Therefore, the class of ionic liquid, which is both a Lewis and Brønsted acid, is of value for esterifications. Nevertheless, some drawbacks restrict their widespread applications. Firstly, most ionic liquids have high liquid viscosity, which can increase their mass and heat transfer rate. Secondly, ionic liquid catalysts are harder to recycle and separate from reaction systems than solid catalysts, which can increase the number of separation and neutralization steps. Besides, most ionic liquids are expensive, which can vastly affect the cost of industrialization. ${ }^{19,20}$ To solve these problems, some studies reported the concept of 
immobilized ionic liquids. ${ }^{\mathbf{2 1}, \mathbf{2 2}}$ The immobilization process could transfer the desired properties of the ionic liquid to the carrier and convert the homogeneous catalyst to a heterogeneous one, which would greatly reduce waste and pollution.

Mesoporous molecular sieves (e.g. MCM-41, and SBA-15, etc.) are often used as excellent carriers due to their large specific surface areas and pore sizes. ${ }^{\mathbf{2 3 2 4}}$ Recently, many researchers have introduced metals or other acid functional groups into pore structures to change the properties of mesoporous molecular sieves. ${ }^{25,26}$ For example, Mutlu et al. reported that $\mathrm{Zr}$ SBA-15 was used as a catalyst for the esterification of cetyl alcohol with palmitic acid in $63.1 \%$ yield. ${ }^{27}$ However, there is still some efforts required to enhance their performance. The concept of introducing ionic liquids into mesoporous molecular sieves or metal doped mesoporous molecular sieves combines the advantages of two materials, which could exhibit more outstanding performances.

In this study, a Brønsted and Lewis acid ionic liquid [mimps]Cl- $\mathrm{ZnCl}_{2}$ was synthesized and immobilized on the $\mathrm{Zr}-\mathrm{SBA}-15$ mesoporous molecular sieves for the first time. The catalytic activity of $\mathrm{Zr}-\mathrm{SBA}-15 /[\mathrm{mim}-\mathrm{ps}] \mathrm{Cl}-\mathrm{ZnCl}_{2}$ is investigated in the esterification of acetic acid with $n$ - $\mathrm{BuOH}$ (or $\mathrm{BnOH}$, Naxol). The effect of the reaction time, reaction temperature, dose of the catalyst and reactant molar ratio on the esterification was systematically studied. The results showed that, among three kinds of esterification, the esterification of acetic acid with $\mathrm{BnOH}$ on the $\mathrm{Zr}-\mathrm{SBA}-15 /[\mathrm{mim}-\mathrm{ps}] \mathrm{Cl}-\mathrm{ZnCl}_{2}$ catalyst exhibited the highest acetic acid conversion with $93.6 \%$. The catalytic activity of the $\mathrm{Zr}-\mathrm{SBA}-15 /[\mathrm{mim}-\mathrm{ps}] \mathrm{Cl}-\mathrm{ZnCl}_{2}$ sample is much higher than that of Zr-SBA-15.

\section{Experimental}

\subsection{Materials}

The poly(ethylene glycol)-block-poly(propylene glycol)-blockpoly(ethylene glycol) (Pluronic P123), used as the structure- directing agent in the $\mathrm{Zr}-\mathrm{SBA}-15$ synthesis process, was purchased from Aldrich Company. 1-methylimidazole (>99\%), 1,3-propane sulfone (>99\%), zinc chloride, toluene (98\%), tetraethoxy silane (TEOS), zirconium oxychloride, sodium chloride, hydrochloric acid (37 wt\%), anhydrous ether (98\%), methyl alcohol (98\%), acetic acid (98\%), n-butyl alcohol (98\%), benzyl alcohol (98\%) and cyclohexanol (98\%), used in the experiment, were of analytical grade and were purchased from the Shanghai Chemical Reagent Corporation, China.

\subsection{Synthesis of $\mathrm{Zr}-\mathrm{SBA}-15$}

Zr-SBA-15 molecular sieves with different amounts of $\mathrm{Zr}$ were synthesized in a self-generated acidic environment. ${ }^{28}$ Typically, $2.0 \mathrm{~g}$ of P123 was dissolved in $90 \mathrm{~mL}$ of distilled water at $35^{\circ} \mathrm{C}$ to form a transparent solution. Then, $1.18 \mathrm{~g}$ of $\mathrm{NaCl}$ and various amounts of $\mathrm{ZrOCl}_{2}$ were added to the above solution. After stirring for $2 \mathrm{~h}$ at $35^{\circ} \mathrm{C}, 4.5 \mathrm{~mL}$ of TEOS was added to the mixed solution. The mixture was stirred for $24 \mathrm{~h}$, and then transferred into a $100 \mathrm{~mL}$ Teflon-lined autoclave and crystallized for $24 \mathrm{~h}$ at $90{ }^{\circ} \mathrm{C}$. After cooling to room temperature, the product was filtered and washed with a large amount of distilled water and dried at 50-60 ${ }^{\circ} \mathrm{C}$ for $24 \mathrm{~h}$. The as-synthesized $\mathrm{Zr}-\mathrm{SBA}-15$ sample was heated to $550{ }^{\circ} \mathrm{C}$ at a heating rate of $2{ }^{\circ} \mathrm{C} \min ^{-1}$ and calcined at $550{ }^{\circ} \mathrm{C}$ in air for $6 \mathrm{~h}$ to remove the template. The resulting sample was denoted as $\mathrm{Zr}-\mathrm{SBA}-15(X)$, where $X$ is the $\mathrm{Si}$ / $\mathrm{Zr}$ molar ratio in the synthesis gel from 40,20 to 10 .

\subsection{Synthesis of [mim-ps]Cl- $\mathrm{ZnCl}_{2}$}

The synthesis of the Lewis and Brønsted acid ionic liquid [mim$\mathrm{ps}] \mathrm{Cl}-\mathrm{ZnCl}_{2}$ was carried out according to ref. 16 . Briefly, $6.1 \mathrm{~g}$ of 1,3-propane sulfone was added to $30 \mathrm{~mL}$ toluene with vigorous stirring to obtain a transparent solution at $50{ }^{\circ} \mathrm{C}$. Then, $4.1 \mathrm{~g}$ of $\mathrm{N}$-methylimidazole was dropped slowly into the above solution. After stirring for $3 \mathrm{~h}$, the resulting white precipitate was filtered and washed with $25 \mathrm{~mL}$ diethyl ether 3 times, and dried at $60^{\circ} \mathrm{C}$
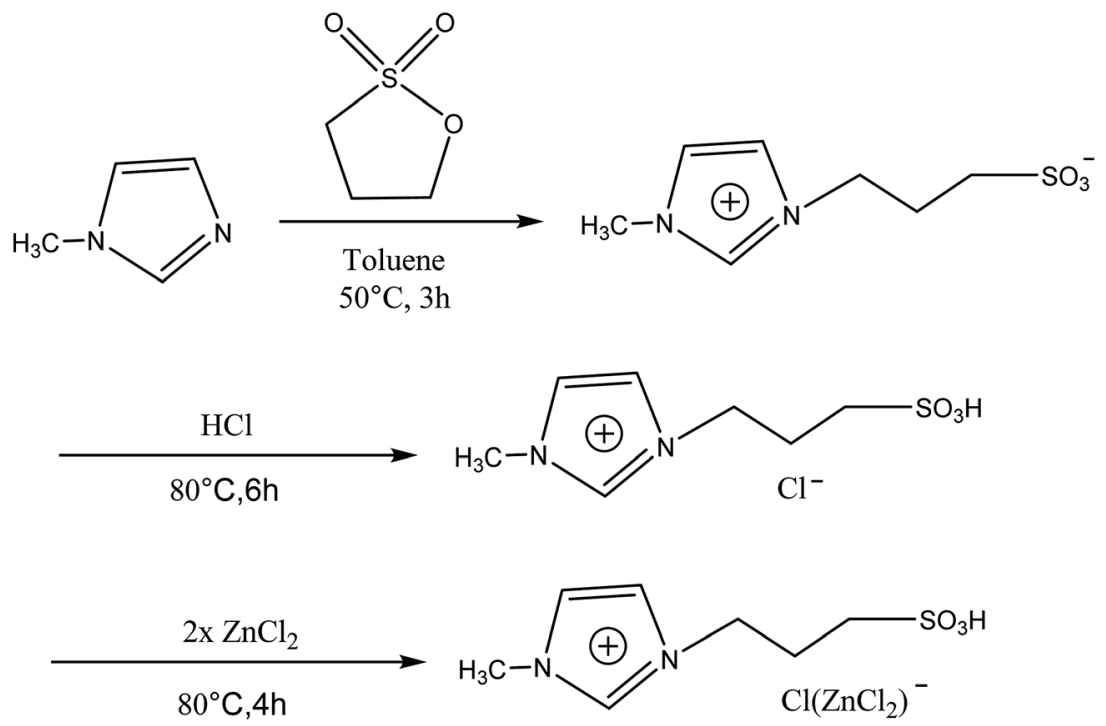

Scheme 1 A possible synthesis process of $[\mathrm{mim}-\mathrm{ps}] \mathrm{Cl}-\mathrm{ZnCl}_{2}$. 
for $6 \mathrm{~h}$ to obtain the dried sample. After that, a stoichiometric amount of $\mathrm{HCl}$ was added slowly to the precursor solid under stirring to form a transparent solution at room temperature. The above solution was stirred at $80{ }^{\circ} \mathrm{C}$ for $3 \mathrm{~h}$ and dried under vacuum at $90{ }^{\circ} \mathrm{C}$ to generate $[\mathrm{mim}-\mathrm{ps}] \mathrm{Cl}$. Then, under stirring, two equiv. of $\mathrm{ZnCl}_{2}$ was added slowly to [mim-ps] Cl at $80^{\circ} \mathrm{C}$ for $4 \mathrm{~h}$ to form [mim-ps]Cl- $\mathrm{ZnCl}_{2}$. According to the above preparation details, a possible synthesis process of $[\mathrm{mim}-\mathrm{ps}] \mathrm{Cl}-\mathrm{ZnCl}_{2}$ is displayed in Scheme 1.

\subsection{Synthesis of the $\mathrm{Zr}-\mathrm{SBA}-15 /[\mathrm{mim}-\mathrm{ps}] \mathrm{Cl}-\mathrm{ZnCl}_{2}$ catalyst}

$\mathrm{Zr}-\mathrm{SBA}-15(X) /[\mathrm{mim}-\mathrm{ps}] \mathrm{Cl}-\mathrm{ZnCl}_{2}$ was synthesized according to the mass ratio of $1 \mathrm{~g} \mathrm{Zr}-\mathrm{SBA}-15(X): 1.5 \mathrm{~g}$ [mim-ps]Cl-ZnCl${ }_{2}$. In a typical preparation process: $6 \mathrm{~g}$ of $[\mathrm{mim}-\mathrm{ps}] \mathrm{Cl}-\mathrm{ZnCl}_{2}$ was added to $50 \mathrm{~mL}$ methyl alcohol at $40{ }^{\circ} \mathrm{C}$. After stirring for $30 \mathrm{~min}$, a transparent solution was obtained, and then $4 \mathrm{~g}$ of $\mathrm{Zr}-$ SBA-15 $(X)$ was added to the solution. Thereafter, the mixture was continuously stirred for $24 \mathrm{~h}$ at $40{ }^{\circ} \mathrm{C}$. Finally, methyl alcohol was distilled, and the resulting solid was washed three times with $20 \mathrm{~mL}$ diethyl ether and dried at $60{ }^{\circ} \mathrm{C}$ for $12 \mathrm{~h}$.

\subsection{Characterization}

The functional groups of the samples were characterized by FT-IR spectroscopy using a (Nexus FT-IR 470) spectrometer, made by Nicolet Corporation (USA) with a $\mathrm{KBr}$ pellet technique in the frequency range of $4000-400 \mathrm{~cm}^{-1}$. The surface areas and pore sizes of the samples were measured using a surface area and porosity analyzer (ASAP 2020 HD88, made by Micromeritics Instrument Corporation, USA). The surface areas and pore sizes were calculated using the Brunauer-Emmett-Teller (BET) and Barrett-Joyner-Halenda (BJH) methods, respectively. The powder X-ray diffraction (XRD) was performed with a Rigaku D/MAX 2500PC instrument using $\mathrm{Cu} \mathrm{K} \alpha$ radiation $(\lambda=0.15418 \mathrm{~nm})$, operated at $40 \mathrm{kV}$ and $50 \mathrm{~mA}$ with a scan step of $0.02^{\circ}$ from $0.5^{\circ}$ to $5^{\circ}(2 \theta)$ at a speed of $1^{\circ} \mathrm{min}^{-1}$. Transmission electron microscopy (TEM) microphotographs were obtained using a Philips TEMCNAI-12 microscope with an acceleration voltage of $120 \mathrm{kV}$. X-ray photoelectron spectroscopy (XPS) measurements were recorded on an ESCALAB 250 (Thermal Electron Corp.) spectrometer equipped with an $\mathrm{Al} \mathrm{K} \alpha \mathrm{X}$-ray source, operating at $150 \mathrm{~W}$. The binding energies were referenced to the $\mathrm{C}$ 1s binding energy at $284.8 \mathrm{eV}$. The elemental analysis of a sample was determined using the inductive coupled plasma (ICP) technique (Vista-MPX, Australia), and the detector was an MPX CCD. The thermal properties of the samples were measured on a thermogravimetric analyser (TGA-DSC, STA 449C) in air $\left(50 \mathrm{~mL} \mathrm{~min}{ }^{-1}\right)$ from 0 to $800{ }^{\circ} \mathrm{C}$ with a heating rate of $10^{\circ} \mathrm{C} \mathrm{min}^{-1}$, held for $5 \mathrm{~min}$ and cooled down to room temperature.

\subsection{Esterification of acetic acid with $n$-butyl alcohol, benzyl alcohol and cyclohexanol}

The reaction was carried out in liquid phase under atmospheric pressure. Taking the esterification of acetic acid with benzyl alcohol as an example, $6 \mathrm{~g}$ of acetic acid was added to a 3-neck boiling flask equipped with magnetic stirring and a reflux condensing tube. After heating to the required temperature,

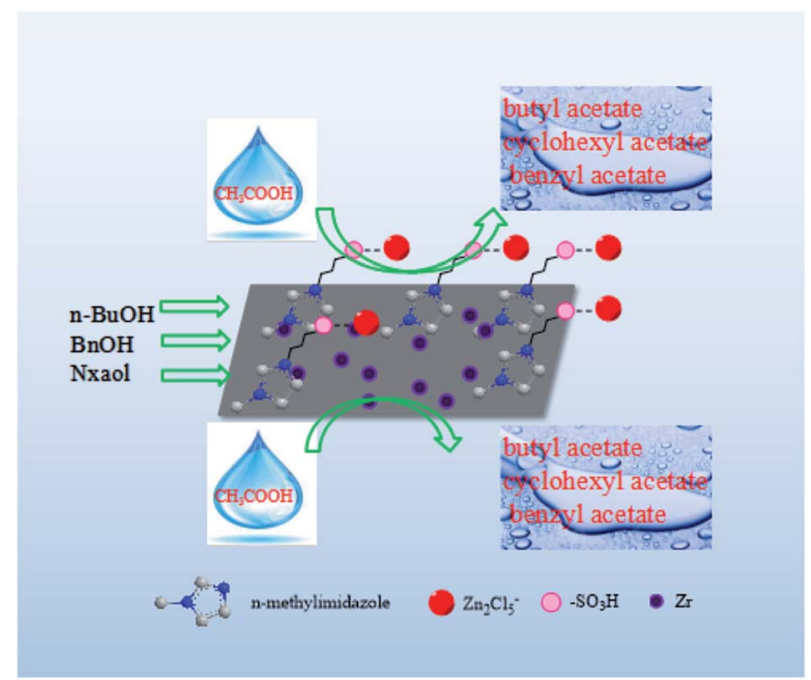

Scheme 2 The esterification of acetic acid with $n$-butyl alcohol, benzyl alcohol and cyclohexanol.

$10.8 \mathrm{~g}$ of benzyl alcohol and $0.4 \mathrm{~g}$ of catalyst were added to the above solution. After reacting for $5 \mathrm{~h}$, the solution was cooled down to room temperature and centrifuged to obtain the catalyst. The catalyst was washed with $20 \mathrm{~mL}$ of diethyl ether and dried under $60{ }^{\circ} \mathrm{C}$ for reuse. The product was analyzed by an SP2000 gas chromatograph fitted with an SE-54 capillary column coupled with FID. It may be speculated that in the mechanism of esterification with a solid acid catalyst the protonated carboxylic acid and the protonated alcohol intermediate compete to form in the Brønsted and Lewis sites in the solid acid catalyst, ${ }^{\mathbf{2 9 , 3 0}}$ and the presence of an ionic liquid could greatly accelerate this process. A probable mechanism for the esterification is shown in Scheme 2.

\section{Results and discussion}

\subsection{XRD analysis}

The XRD patterns of all of the samples are displayed in Fig. 1. As shown in Fig. 1, all of the samples had diffraction peaks at $c a$. $0.9^{\circ}, 1.51^{\circ}$, and $1.75^{\circ}$ indexed to (100), (110) and (200), respectively. It indicates that all of the samples had a $2 \mathrm{D}$-hexagonal p6mm structure. ${ }^{31}$ Furthermore, it is noted from Fig. 1 that little difference is observed in the XRD patterns of the Zr-SBA15(10), Zr-SBA-15(20) and Zr-SBA-15(40) samples, and this probably suggests that, to some extent, increasing $\mathrm{Zr}$ incorporation does not affect the mesoporous ordering of the samples; the same results were also observed in ref. 32. However, after introducing [mim-ps] Cl- $\mathrm{ZnCl}_{2}$ into the $\mathrm{Zr}-\mathrm{SBA}-15$ mesoporous materials, the resulting $\mathrm{Zr}-\mathrm{SBA}-15 /[\mathrm{mim}-\mathrm{ps}] \mathrm{Cl}-\mathrm{ZnCl}_{2}$ samples had mesoporous structures, but the peak intensities greatly declined. This may be due to the occupation of the ionic liquid in the pore structure. ${ }^{33}$

\subsection{Analysis of physical nitrogen adsorption}

The $\mathrm{N}_{2}$ adsorption-desorption isotherms of all of the samples are shown in Fig. 2. As shown in Fig. 2, all of the isotherms were 


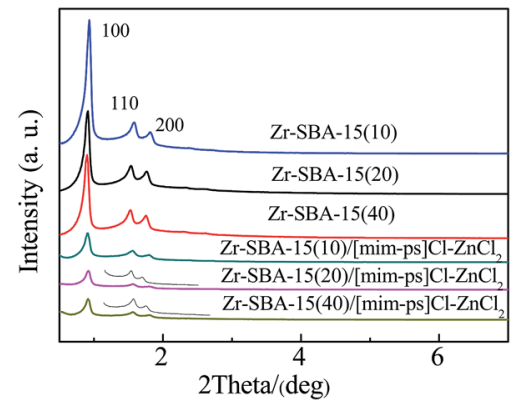

Fig. 1 XRD patterns of various samples.

typical IV isotherms with a $\mathrm{H} 1$ hysteresis loop as defined by IUPAC, which was analogous to conventional SBA-15. ${ }^{34}$ The corresponding textural properties are summarized in Table 1, including surface area, average pore size, and pore volume. Table 1 shows that with an increase of $\mathrm{Zr}$ doping in the silicate species, the specific surface area decreased and the average pore size gradually increased. Compared to the corresponding carrier, the specific surface area of the composite catalyst obtained after loading the ionic liquid greatly decreased and the average pore size increased a lot. On the other hand, the amount of $\mathrm{Zn}$ ions was detected by ICP-AES, and from this value the $[\mathrm{mim}-\mathrm{ps}] \mathrm{Cl}-\mathrm{ZnCl}_{2}$ content was calculated. As shown in Table 1 , it is noted that the [mim-ps]Cl- $\mathrm{ZnCl}_{2}$ content in $\mathrm{Zr}-$ SBA-15(10)/[mim-ps]Cl-ZnCl, Zr-SBA-15(20)/[mim-ps]Cl-ZnCl ${ }_{2}$ and $\mathrm{Zr}-\mathrm{SBA}-15(40) /[\mathrm{mim}-\mathrm{ps}] \mathrm{Cl}-\mathrm{ZnCl}_{2}$ was $44 \%, 47 \%$ and $49 \%$, respectively.

\subsection{FT-IR analysis}

Fig. 3 displays the FT-IR spectra of Zr-SBA-15(10), [mim-ps]Cl$\mathrm{ZnCl}_{2}$ and $\mathrm{Zr}-\mathrm{SBA}-15(10) /[\mathrm{mim}-\mathrm{ps}] \mathrm{Cl}-\mathrm{ZnCl}_{2}$. The peak at 2961 $\mathrm{cm}^{-1}$ for $[\mathrm{mim}-\mathrm{ps}] \mathrm{Cl}-\mathrm{ZnCl}_{2}$ was caused by the $\mathrm{C}-\mathrm{H}$ stretching vibration of straight-chain paraffin. Its flexural vibration was observed at $1337 \mathrm{~cm}^{-1}$ and $1460 \mathrm{~cm}^{-1}$, respectively. The adsorption bands at $3111 \mathrm{~cm}^{-1}$ and $3154 \mathrm{~cm}^{-1}$ were characteristic of the $\mathrm{C}-\mathrm{H}$ stretching vibration of the imidazole ring and
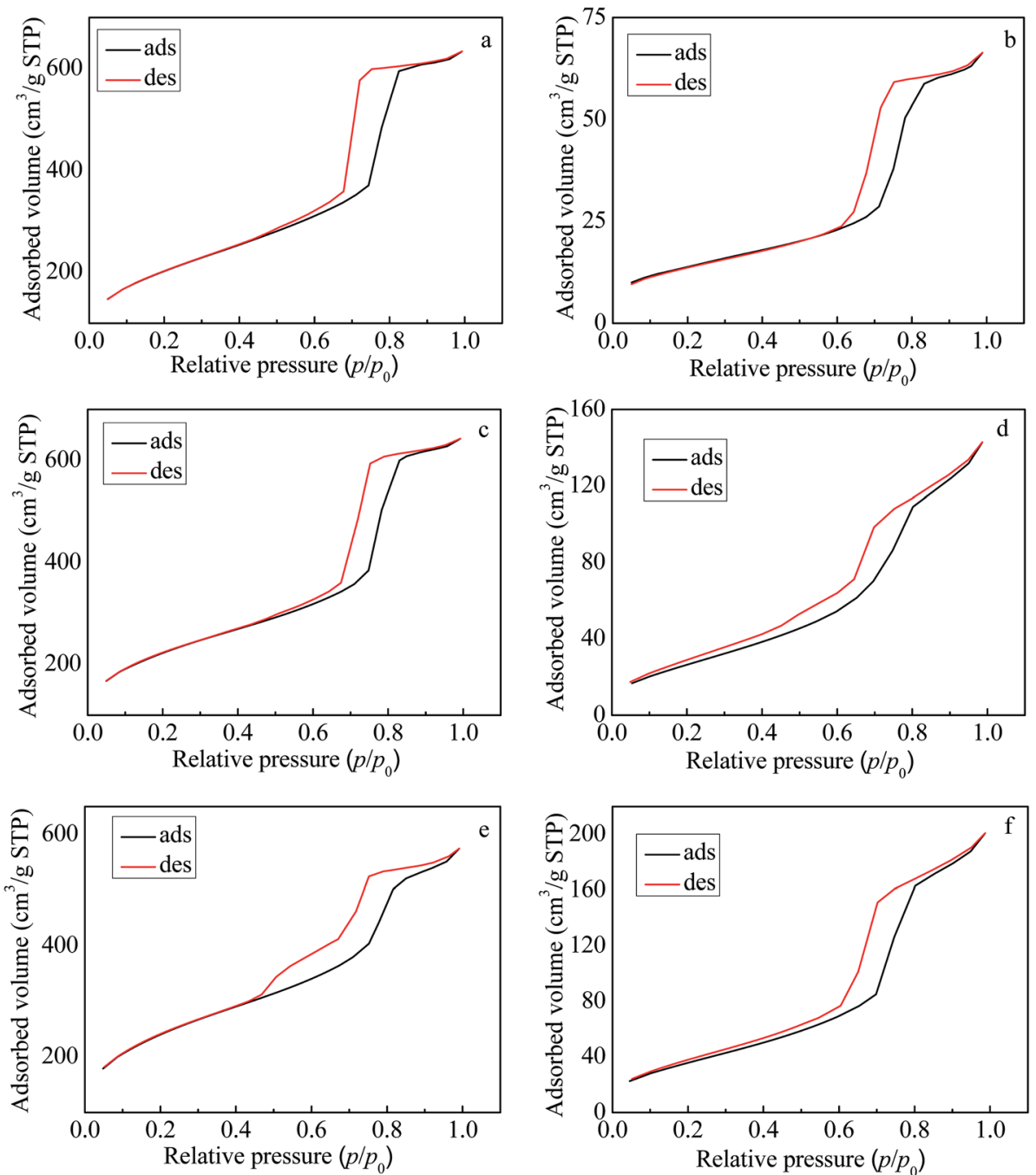

Fig. $2 \mathrm{~N}_{2}$ adsorption-desorption isotherms of various samples (a) $\mathrm{Zr}-\mathrm{SBA}-15(10)$; (b) $\mathrm{Zr}-\mathrm{SBA}-15(10) /[\mathrm{mim}-\mathrm{ps}] \mathrm{Cl}-\mathrm{ZnCl}$; (c) $\mathrm{Zr}-\mathrm{SBA}-15(20) ;(\mathrm{d})$ $\mathrm{Zr}-\mathrm{SBA}-15(20) /[\mathrm{mim}-\mathrm{ps}] \mathrm{Cl}-\mathrm{ZnCl}_{2}$; (e) $\mathrm{Zr}-\mathrm{SBA}-15(40)$; (f) $\mathrm{Zr}-\mathrm{SBA}-15(40) /[\mathrm{mim}-\mathrm{ps}] \mathrm{Cl}-\mathrm{ZnCl}_{2}$. 
Table 1 Textural properties of various samples and the ionic liquid content in the composites

\begin{tabular}{|c|c|c|c|c|}
\hline Sample & $\begin{array}{l}{[\mathrm{mim}-\mathrm{ps}] \mathrm{Cl}-\mathrm{ZnCl}_{2}} \\
\text { wt } \%\end{array}$ & $\begin{array}{l}\text { Surface area } \\
\left(\mathrm{m}^{2} \mathrm{~g}^{-1}\right)\end{array}$ & $\begin{array}{l}\text { Average pore } \\
\text { size (nm) }\end{array}$ & $\begin{array}{l}\text { Pore volume } \\
\left(\mathrm{cm}^{3} \mathrm{~g}^{-1}\right)\end{array}$ \\
\hline 10-Zr-SBA-15 & - & 716.3 & 5.4 & 0.82 \\
\hline 40-Zr-SBA-15 & - & 845.6 & 4.2 & 0.95 \\
\hline 10-Zr-SBA-15/[mim-ps]Cl-ZnCl & 44 & 49.9 & 7.4 & 0.11 \\
\hline 20-Zr-SBA-15/[mim-ps]Cl-ZnCl & 47 & 104.7 & 7.6 & 0.22 \\
\hline
\end{tabular}

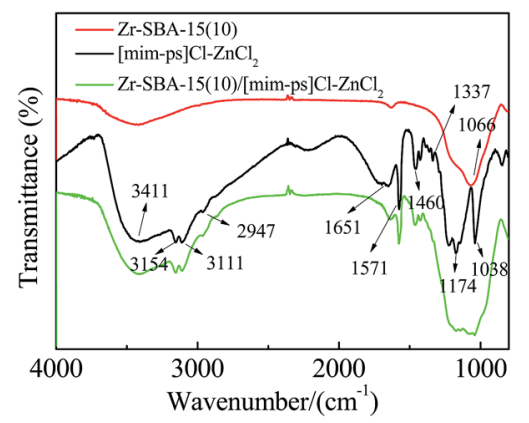

Fig. 3 FT-IR spectra of $\mathrm{Zr}-\mathrm{SBA}-15(10)$, [mim-ps]Cl- $\mathrm{ZnCl}_{2}$ and $\mathrm{Zr}-$ SBA-15(10)/[mim-ps]Cl-ZnCl .

the peak at $3411 \mathrm{~cm}^{-1}$ was attributed to water absorbed in the ionic liquid. The adsorption bands at $1637 \mathrm{~cm}^{-1}$ and $1571 \mathrm{~cm}^{-1}$ were assigned to $\mathrm{C}=\mathrm{C}$ and $\mathrm{C}=\mathrm{N}$ bonds. Besides, the bands around $1038 \mathrm{~cm}^{-1}$ and $1174 \mathrm{~cm}^{-1}$ were attributed to the $\mathrm{S}=\mathrm{O}$ asymmetric and symmetric stretching vibrations of the $-\mathrm{SO}_{3} \mathrm{H}$ group. Also, it can be noted that the above peaks were observed in the FT-IR spectra of $\mathrm{Zr}-\mathrm{SBA}-15 /[\mathrm{mim}-\mathrm{ps}] \mathrm{Cl}-\mathrm{ZnCl}_{2}$, suggesting that $[\mathrm{mim}-\mathrm{ps}] \mathrm{Cl}-\mathrm{ZnCl}_{2}$ was successfully attached to the carriers. $^{35,36}$

\subsection{XPS analysis}

Fig. 4 shows the high-resolution XPS spectra of the Zr-SBA15(10)/[mim-ps]Cl- $\mathrm{ZnCl}_{2}$ sample. As shown in Fig. 4a, it was noted that the surface of the sample consisted of $\mathrm{O}, \mathrm{Si}, \mathrm{Zr}, \mathrm{C}$, $\mathrm{N}, \mathrm{S}, \mathrm{Cl}$ and $\mathrm{Zn}$ elements. The N, Zn, S, and Cl elements mainly came from the immobilized [mim-ps] Cl- $\mathrm{ZnCl}_{2}$. The $\mathrm{C}$ may be due to the immobilized [mim-ps] Cl- $\mathrm{ZnCl}_{2}$ and the $\mathrm{C}$ absorbed in the air. O, Si and $\mathrm{Zr}$ elements were primarily attributed to Zr-SBA-15. Besides, Fig. 4b shows the XPS Zr 3d high resolution spectra of $\mathrm{Zr}-\mathrm{SBA}-15 /[\mathrm{mim}-\mathrm{ps}] \mathrm{Cl}-\mathrm{ZnCl}_{2}$ with deconvolution peaks. According to Fig. $4 \mathrm{~b}$, the binding energy of $\mathrm{Zr} 3 \mathrm{~d}_{5 / 2}$ was $183.28 \mathrm{eV}$, which was in close proximity to that of $\mathrm{ZrSiO}_{4}$ $(183.3 \mathrm{eV}),{ }^{37}$ suggesting that $\mathrm{Zr}$ ions were incorporated into the framework of SBA-15. Furthermore, the XPS Zn 2p high resolution spectra are presented in Fig. 4c. The binding energy of $\mathrm{Zn} 2 \mathrm{p}_{3 / 2}(1022.4 \mathrm{eV})$ was higher than that of $\mathrm{ZnCl}_{2}$ $(1021.7 \mathrm{eV})$, which was probably because the $\mathrm{Cl}$ ions in [mimps]Cl were combined with $\mathrm{ZnCl}_{2}$ which increased the binding energy of $\mathrm{Zn} 2 \mathrm{p}_{3 / 2} \cdot{ }^{38}$ This indicated the formation of [mim-ps] $\mathrm{Cl}-\mathrm{ZnCl}_{2}$.

\subsection{Acidity measurements}

Fig. 5 shows the FT-IR spectra of [mim-ps]Cl- $\mathrm{ZnCl}_{2}$ using acetonitrile as a probe. Two characteristic peaks at $2253 \mathrm{~cm}^{-1}$ and $2293 \mathrm{~cm}^{-1}$ were observed in the FT-IR spectra of acetonitrile, due to the $\mathrm{CN}$ stretching vibrations, while a new absorption band at $2293 \mathrm{~cm}^{-1}$ appeared when [mim-ps]Cl- $\mathrm{ZnCl}_{2}$ was added to acetonitrile. This was attributed to acetonitrile coordinating with the Lewis acid sites, suggesting that [mim-ps]Cl$\mathrm{ZnCl}_{2}$ had Lewis acidity. Fig. 6 presents the FT-IR spectra of [mim-ps]Cl- $\mathrm{ZnCl}_{2}$ using pyridine as a probe. The absorption peak at $1437 \mathrm{~cm}^{-1}$ was observed in the FT-IR spectra of pyridine. Furthermore, we found that when [mim-ps]Cl- $\mathrm{ZnCl}_{2}$ was added to the pyridine, this band shifted to $1450 \mathrm{~cm}^{-1}$, which was known as the characteristic peak of pyridine coordinated with the Lewis acid sites, agreeing with the result of the FT-IR spectra of $[\mathrm{mim}-\mathrm{ps}] \mathrm{Cl}-\mathrm{ZnCl}_{2}$ using acetonitrile as a probe. At the same time, the characteristic peak of pyridine coordinated with the Brønsted acid sites was observed at $1539 \mathrm{~cm}^{-1}$, which suggested that the $[\mathrm{mim}-\mathrm{ps}] \mathrm{Cl}-\mathrm{ZnCl}_{2}$ had Brønsted acidity. ${ }^{39}$

\subsection{TG analysis}

The TGA curves of the Zr-SBA-15(10) and Zr-SBA-15(10)/[mimps]Cl- $\mathrm{ZnCl}_{2}$ samples are shown in Fig. 7. A weight loss at around $100{ }^{\circ} \mathrm{C}$ was observed for both the catalyst and carrier and was assigned to the loss of moisture. In contrast to $\mathrm{Zr}-\mathrm{SBA}$ 15(10), $\mathrm{Zr}-\mathrm{SBA}-15(10) /[\mathrm{mim}-\mathrm{ps}] \mathrm{Cl}-\mathrm{ZnCl}_{2}$ had a more than $30 \%$ weight loss at about $360{ }^{\circ} \mathrm{C}$ to $600{ }^{\circ} \mathrm{C}$ and it was attributed to the degradation of $[\mathrm{mim}-\mathrm{ps}] \mathrm{Cl}-\mathrm{ZnCl}_{2}$.

\subsection{TEM analysis}

The TEM images of the Zr-SBA-15(10) and Zr-SBA-15(10)/[mimps]Cl-ZnCl ${ }_{2}$ samples are shown in Fig. 8. As shown in Fig. 8a, clear pore arrays were observed, suggesting the formation of an ordered mesoporous framework, and this is in agreement with the results of the XRD and BET. At the same time, it was also seen from Fig. 8b that $\mathrm{Zr}-\mathrm{SBA}-15 /[\mathrm{mim}-\mathrm{ps}] \mathrm{Cl}-\mathrm{ZnCl}_{2}$ still had a highly ordered mesoporous structure.

\subsection{Catalytic activity}

3.8.1 Effect of different catalysts on the esterification. Table 2 lists the results of the esterification of acetic acid with $n$ $\mathrm{BuOH}, \mathrm{BnOH}$ and Naxol for all of the samples. To evaluate the performance of these catalysts, the results of the esterification of acetic acid with $n-\mathrm{BuOH}, \mathrm{BnOH}$ and Naxol over concentrated 

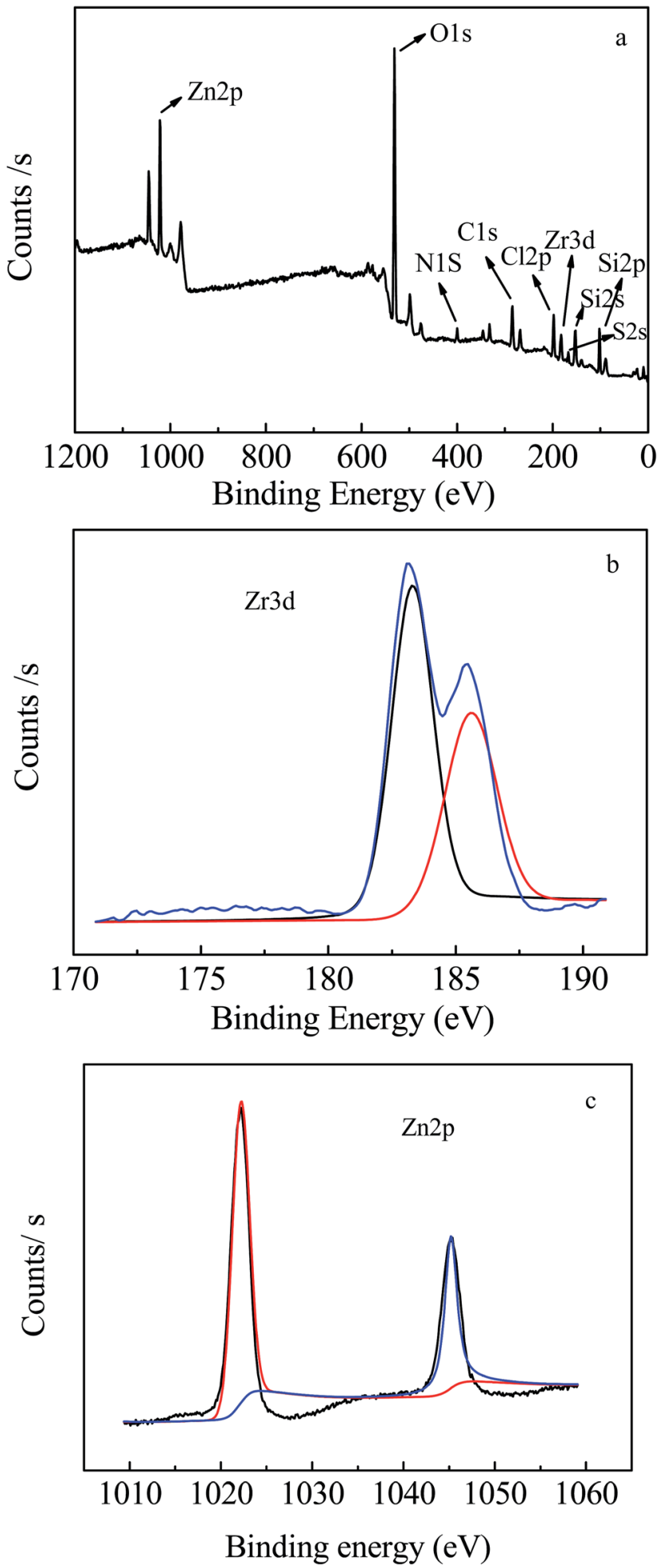

Fig. 4 XPS spectra of several $\mathrm{Zr}-\mathrm{SBA}-15(10) /[\mathrm{mim}-\mathrm{ps}] \mathrm{Cl}-\mathrm{ZnCl}_{2}$ samples (a) survey of samples; (b) Zr 3d; (c) Zn 2p.

sulfuric acid, SBA-15 and a pure ionic liquid were carried out and are also listed in Table 2. In these reactions, a 1.2:1 molar ratio of the alcohol to acetic acid $(6 \mathrm{~g})$ and $0.4 \mathrm{~g}$ of the catalyst were added into the reactor sequentially; the reaction time was $300 \mathrm{~min}$ and the reaction temperature was $100{ }^{\circ} \mathrm{C}$. According to

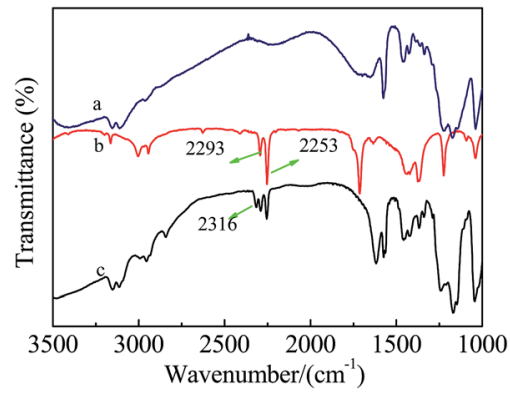

Fig. $5 \mathrm{FT}-\mathrm{IR}$ spectra of $[\mathrm{mim}-\mathrm{ps}] \mathrm{Cl}-\mathrm{ZnCl}_{2}$ using acetonitrile as a probe (a) [mim-ps] Cl- $\mathrm{ZnCl}_{2}$; (b) pure acetonitrile; (c) acetonitrile/ [mim-ps] Cl- $\mathrm{ZnCl}_{2}$ where acetonitrile is $2 / 3$ as a mole fraction.

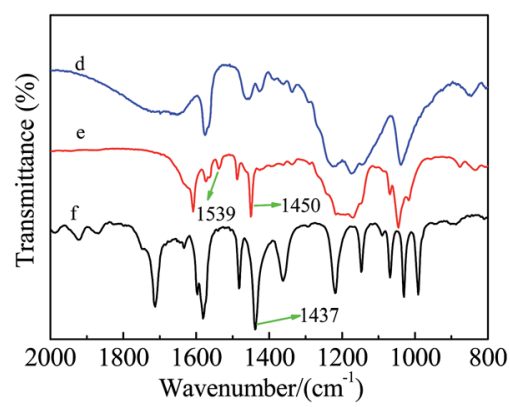

Fig. 6 FT-IR spectra of [mim-ps]Cl- $\mathrm{ZnCl}_{2}$ using pyridine as a probe (d) [mim-ps]Cl- $\mathrm{ZnCl}_{2}$; (e) pyridine/[mim-ps] $\mathrm{Cl}-\mathrm{ZnCl}_{2}$ where pyridine is $2 /$ 3 as a mole fraction; (f) pure pyridine.

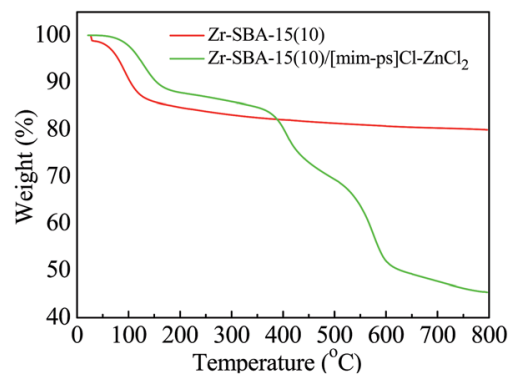

Fig. 7 TGA curves of the $\mathrm{Zr}-\mathrm{SBA}-15(10)$ and $\mathrm{Zr}-\mathrm{SBA}-15(10) /[\mathrm{mim}-\mathrm{ps}]$ $\mathrm{Cl}-\mathrm{ZnCl}_{2}$ samples.

Table 2, Zr-SBA-15(10) exhibited the highest catalytic activity among the three Zr-SBA-15 catalysts for three different esterifications, along with an acetic acid conversion of $61.7 \%, 63.3 \%$ and $55.9 \%$ with $n-\mathrm{BuOH}, \mathrm{BnOH}$ and Naxol, respectively. The catalytic activities of the three Zr-SBA-15 catalysts are much higher than that of the SBA-15 catalyst. However, it was noted that the catalytic activities of the three Zr-SBA-15/[mim-ps]Cl$\mathrm{ZnCl}_{2}$ samples were significantly enhanced compared to their corresponding carriers, which may be due to the introduction of [mim-ps]Cl- $\mathrm{ZnCl}_{2}$ into the $\mathrm{Zr}-\mathrm{SBA}-15$ samples, leading to an increase in the amount of acid in the resulting samples. Among all of the samples, $\mathrm{Zr}-\mathrm{SBA}-15(10) /[\mathrm{mim}-\mathrm{ps}] \mathrm{Cl}-\mathrm{ZnCl}_{2}$ exhibited the highest catalytic activity in the three types of esterification 

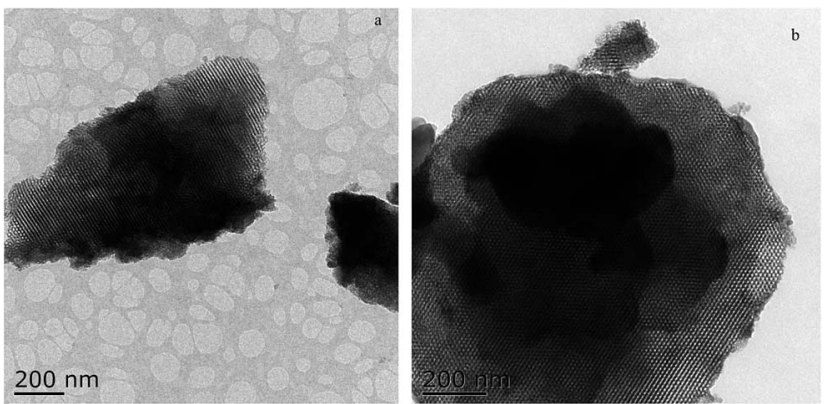

Fig. 8 TEM images of (a) Zr-SBA-15(10) and (b) Zr-SBA-15(10)/[mimps] $\mathrm{Cl}-\mathrm{ZnCl}_{2}$.

under comparable conditions, and gives a maximum acetic acid conversion of $89.7,93.6$, and $84.9 \%$ with $n-\mathrm{BuOH}, \mathrm{BnOH}$ and Naxol, respectively. Furthermore, according to Table 2, we found that the catalytic activity of concentrated sulfuric acid for the three esterifications was low compared to the three composite catalysts. On the other hand, $0.176 \mathrm{~g}$ of pure ionic liquid was also applied as the catalyst which is the same ionic liquid content in $\mathrm{Zr}-\mathrm{SBA}-15(10) /[\mathrm{mim}-\mathrm{ps}] \mathrm{Cl}-\mathrm{ZnCl}_{2}$. The results showed that the acetic acid conversions were much lower than those for $\mathrm{Zr}-\mathrm{SBA}-15(10) /[\mathrm{mim}-\mathrm{ps}] \mathrm{Cl}-\mathrm{ZnCl}_{2}$, at 76.0, 80.8, and $74.1 \%$ with $n-\mathrm{BuOH}, \mathrm{BnOH}$ and Naxol, respectively.

3.8.2 Effect of temperature on the esterification. Fig. 9 shows the effect of temperature on the esterification of acetic acid with $n$-BuOH, BnOH and Naxol over Zr-SBA-15(10)/[mim$\mathrm{ps}] \mathrm{Cl}-\mathrm{ZnCl}_{2}$ at various reaction temperatures, ranging from $70^{\circ} \mathrm{C}$ to $120^{\circ} \mathrm{C}$. In the three esterifications, we found from Fig. 9 that the conversion of acetic acid gradually increased with temperature from $70{ }^{\circ} \mathrm{C}$ to $100{ }^{\circ} \mathrm{C}$. This may be because the increase in the reaction temperature could enhance the molecular collisions and the miscibility of the reactants. When the reaction temperature was increased to $100{ }^{\circ} \mathrm{C}$, the conversion of acetic acid in the esterification of acetic acid with $n$ $\mathrm{BuOH}, \mathrm{BnOH}$ and Naxol over $\mathrm{Zr}-\mathrm{SBA}-15(10) /[\mathrm{mim}-\mathrm{ps}] \mathrm{Cl}-\mathrm{ZnCl}_{2}$ was $89.7 \%, 93.6 \%$ and $84.9 \%$, respectively. Further, it was noted that the conversion of acetic acid in all cases remained almost unchanged with the increase in temperature from $100{ }^{\circ} \mathrm{C}$ to

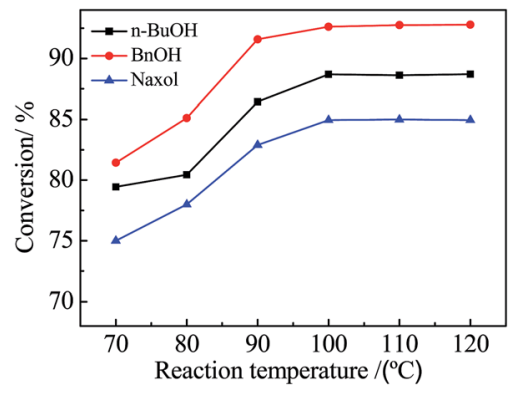

Fig. 9 The effect of temperature on esterification of acetic acid with $n-\mathrm{BuOH}, \mathrm{BnOH}$ and Naxol over $\mathrm{Zr}-\mathrm{SBA}-15(10) /[\mathrm{mim}-\mathrm{ps}] \mathrm{Cl}-\mathrm{ZnCl}_{2}$ catalyst (reaction condition: catalyst dose $=0.4 \mathrm{~g}$; time $=300 \mathrm{~min}$; $n_{\text {alcohol }} / n_{\text {acetic acid }}=1.2$ ).

$120^{\circ} \mathrm{C}$, which is probably due to the enhancement of some sidereaction (e.g. dehydration of alcohol to ether). ${ }^{40}$

3.8.3 Effect of molar ratio of alcohol to acetic acid. The results of effect of the molar ratio of alcohol to acetic acid on the esterification of acetic acid with $n-\mathrm{BuOH}, \mathrm{BnOH}$ and Naxol over the $\mathrm{Zr}-\mathrm{SBA}-15(10) /[\mathrm{mim}-\mathrm{ps}] \mathrm{Cl}-\mathrm{ZnCl}_{2}$ catalyst are shown in Fig. 10. Obviously, a common trend for the three esterifications is that the conversion of acetic acid increased as the molar ratio of alcohol to acetic acid increased from 1.1 to 1.2 , and then gradually decreased from 1.2 to 1.8 . The decrease in acetic acid conversion may be due to excess alcohol in the reactant, resulting in the dilution of acetic acid and the catalyst. In particular, a maximum conversion of acetic acid was noted when the molar ratio of alcohol to acetic acid was 1.2. Among the three esterifications, the conversion of acetic acid in the esterification of acetic acid with $\mathrm{BnOH}$ is the highest and reached 93.6\%, suggesting that Zr-SBA-15(10)/[mim-ps]Cl$\mathrm{ZnCl}_{2}$ is a promising catalyst for the esterification of acetic acid with $\mathrm{BnOH}$.

3.8.4 Effect of catalyst dose on the esterification. The effect of the catalyst dose on the esterification of acetic acid with $n$ $\mathrm{BuOH}, \mathrm{BnOH}$ and Naxol over the Zr-SBA-15(10)/[mim-ps]Cl$\mathrm{ZnCl}_{2}$ catalyst is shown in Fig. 11. The acetic acid conversion in the three esterifications quickly increased as the amount of catalyst increased from 0.1 to $0.4 \mathrm{~g}$, maybe owing to the increase

Table 2 Catalytic activities of the different catalysts ${ }^{a}$

\begin{tabular}{llll}
\hline Catalyst & $\begin{array}{l}\text { Conversion of acetic } \\
\text { acid with } n \text {-BuOH }(\%)\end{array}$ & $\begin{array}{l}\text { Conversion of acetic } \\
\text { acid with BnOH (\%) }\end{array}$ & $\begin{array}{c}\text { Conversion of acetic } \\
\text { acid with Naxol (\%) }\end{array}$ \\
\hline Zr-SBA-15(10) & 61.7 & 63.3 & 55.9 \\
Zr-SBA-15(20) & 54.5 & 58.4 & 49.7 \\
Zr-SBA-15(40) & 41.3 & 49.0 & 32.7 \\
Zr-SBA-15(10)/[mim-ps]Cl-ZnCl 2 & 89.7 & 93.6 & 84.9 \\
Zr-SBA-15(20)/[mim-ps]Cl-ZnCl & 88.9 & 93.1 & 83.7 \\
Zr-SBA-15(40)/[mim-ps]Cl-ZnCl & 88.3 & 82.1 \\
[mim-ps]Cl-ZnCl & 76.0 & 80.8 & 74.1 \\
Concentrated sulfuric acid & 83.5 & 90.0 & 80.9 \\
SBA-15 & 22.7 & 30.3 & 20.1
\end{tabular}

${ }^{a}$ All error ranges were within 1\%. Product selectivity using the composite catalysts for BnOH and Naxol was higher than $99 \%$. Product selectivity for $n$-BuOH was around $96 \%$. 


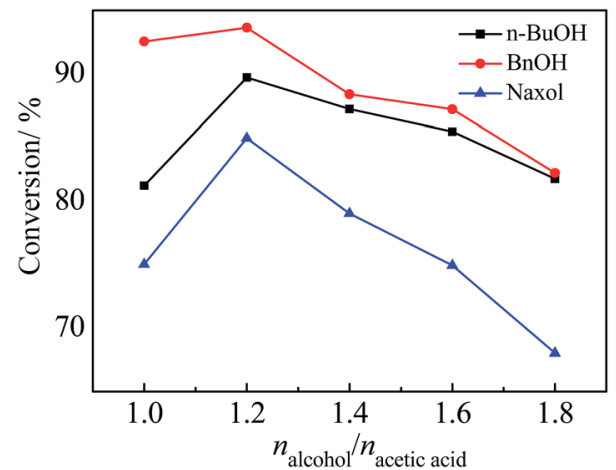

Fig. 10 The effect of the molar ratio of alcohol to acetic acid on the esterification of acetic acid with $n-\mathrm{BuOH}, \mathrm{BnOH}$ and Naxol over the $\mathrm{Zr}-\mathrm{SBA}-15(10) /[\mathrm{mim}-\mathrm{ps}] \mathrm{Cl}-\mathrm{ZnCl}_{2}$ catalyst (reaction conditions: catalyst dose $=0.4 \mathrm{~g}$; time $=300 \mathrm{~min}$; temperature $=100^{\circ} \mathrm{C}$ ).

of active sites in the catalyst caused by the increase in the catalyst dose. However, the acetic acid conversion was almost unchanged when the catalyst dose was in the range of $0.4-0.8 \mathrm{~g}$. This might due to the esterification reaching equilibrium when the catalyst dose is $0.4 \mathrm{~g}$.

3.8.5 Effect of reaction time on the esterification. The esterification of acetic acid with $n-\mathrm{BuOH}, \mathrm{BnOH}$ and Naxol over the $\mathrm{Zr}-\mathrm{SBA}-15(10) /[\mathrm{mim}-\mathrm{ps}] \mathrm{Cl}-\mathrm{ZnCl}_{2}$ catalyst was carried out for a reaction time of $420 \mathrm{~min}$ and the results are presented in Fig. 12. As shown in Fig. 12, we found that, in all cases, the acetic acid conversion quickly increased within $180 \mathrm{~min}$, and then gradually increased to a maximum of $89.7,93.6$, and $84.9 \%$ for $n-\mathrm{BuOH}, \mathrm{BnOH}$ and $\mathrm{Naxol}$ in $300 \mathrm{~min}$, respectively. The acetic acid conversion in the three esterifications was almost unchanged in the reaction time range of $300-420 \mathrm{~min}$, suggesting that the esterification reaction reached equilibrium in $300 \mathrm{~min}$.

\subsection{Reusability of the catalyst}

The reusability of the $\mathrm{Zr}-\mathrm{SBA}-15(10) /[\mathrm{mim}-\mathrm{ps}] \mathrm{Cl}-\mathrm{ZnCl}_{2}$ catalyst was evaluated using the esterification of acetic acid with $\mathrm{BnOH}$

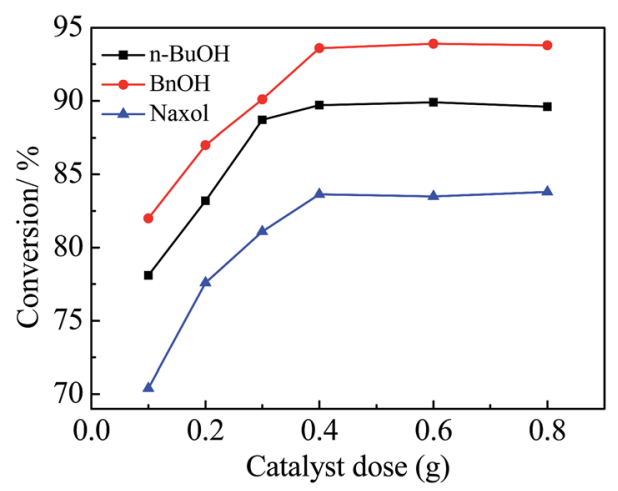

Fig. 11 The effect of catalyst dose on the esterification of acetic acid with $n-\mathrm{BuOH}, \mathrm{BnOH}$ and Naxol over the $\mathrm{Zr}-\mathrm{SBA}-15(10) /[\mathrm{mim}-\mathrm{ps}] \mathrm{Cl}-$ $\mathrm{ZnCl}_{2}$ catalyst (reaction conditions: $n_{\text {alcohol }} / n_{\text {acetic acid }}=1.2$; time $=$ $300 \mathrm{~min}$; temperature $=100^{\circ} \mathrm{C}$ ).

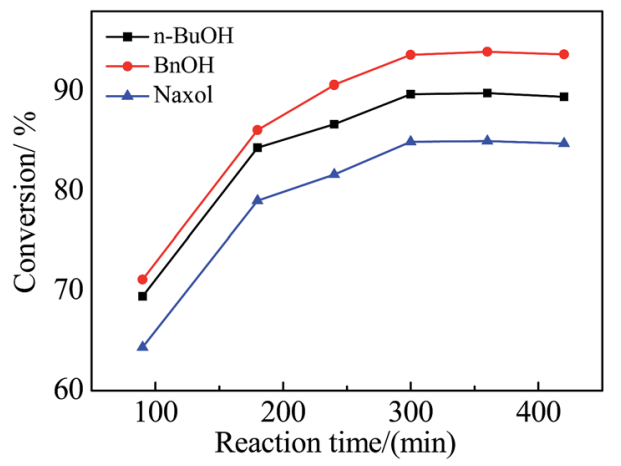

Fig. 12 The effect of reaction time on the esterification of acetic acid with $n-\mathrm{BuOH}, \mathrm{BnOH}$ and Naxol over the $\mathrm{Zr}-\mathrm{SBA}-15(10) /[\mathrm{mim}-\mathrm{ps}] \mathrm{Cl}-$ $\mathrm{ZnCl}_{2}$ catalyst (reaction conditions: $n_{\text {alcohol }} / n_{\text {acetic acid }}=1.2$; catalyst dose $=0.4 \mathrm{~g}$; temperature $=100^{\circ} \mathrm{C}$ ).

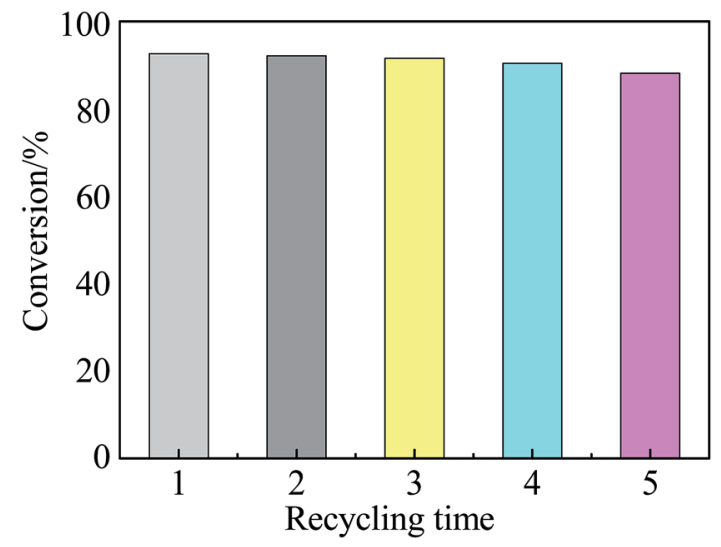

Fig. 13 The reusability of the $\mathrm{Zr}-\mathrm{SBA}-15(10) /[\mathrm{mim}-\mathrm{ps}] \mathrm{Cl}-\mathrm{ZnCl}_{2}$ catalyst (reaction conditions: $n_{\text {alcohol }} / n_{\text {acetic acid }}=1.2$; catalyst dose $=$ $0.4 \mathrm{~g}$; time $=300 \mathrm{~min}$; temperature $=100^{\circ} \mathrm{C}$ ).

under optimal experimental conditions and the results are shown in Fig. 13. According to Fig. 13, it is noted that the acetic acid conversion decreased from $93.6 \%$ to $89.1 \%$ after 5 recycling runs, a decrease of only $4.5 \%$ in acetic acid conversion. This suggested that the $\mathrm{Zr}-\mathrm{SBA}-15(10) /[\mathrm{mim}-\mathrm{ps}] \mathrm{Cl}-\mathrm{ZnCl}_{2}$ catalyst has good stability and reusability. The decrease in acetic acid conversion may be due to the loss of the Zr-SBA-15(10)/[mim$\mathrm{ps}] \mathrm{Cl}-\mathrm{ZnCl}_{2}$ catalyst during the recycling.

\section{Conclusions}

Zr-SBA-15 mesoporous molecular sieves with different Si/Zr molar ratios were hydrothermally synthesized and several $\mathrm{Zr}-$ SBA-15/[mim-ps]Cl-ZnCl 2 catalysts with Brønsted-Lewis acidic ionic liquids were synthesized by the wet impregnation method. $\mathrm{N}_{2}$ physical adsorption, XRD and TEM analysis revealed that the resulting Zr-SBA-15/[mim-ps] $\mathrm{Cl}^{-\mathrm{ZnCl}_{2}}$ catalysts still had good mesoporous frameworks. Compared to the Zr-SBA-15 mesoporous molecular sieve, the catalytic activity of the $\mathrm{Zr}-\mathrm{SBA}-15 /$ [mim-ps]Cl- $\mathrm{ZnCl}_{2}$ catalyst in the esterification of acetic acid with $n-\mathrm{BuOH}, \mathrm{BnOH}$ and Naxol was obviously enhanced. The 
optimal reaction conditions are as follows: the molar ratio of alcohol to acetic acid $=1.2$, time $=300 \mathrm{~min}$, temperature $=$ $100{ }^{\circ} \mathrm{C}$, and catalyst dose $=0.4 \mathrm{~g}$. Under comparable conditions, the $\mathrm{Zr}-\mathrm{SBA}-15(10) /[\mathrm{mim}-\mathrm{ps}] \mathrm{Cl}-\mathrm{ZnCl}_{2}$ catalyst exhibited the highest catalytic activity among the three esterifications and a maximum acetic acid conversion of $93.6 \%$ was achieved in the esterification of acetic acid with $\mathrm{BnOH}$. Zr-SBA-15/[mim-ps]Cl$\mathrm{ZnCl}_{2}$ is a promising catalyst for the esterification of acetic acid with $\mathrm{BnOH}$. The reusability test suggested that $\mathrm{Zr}-\mathrm{SBA}-15 /[\mathrm{mim}-$ ps]Cl- $\mathrm{ZnCl}_{2}$ had good stability.

\section{Acknowledgements}

Financial support from Project supported by the National Natural Science Foundation of China (51572115) is gratefully acknowledged.

\section{References}

1 S. R. Kirumakki, N. Nagaraju, K. V. V. S. B. S. R. Murthy and S. Narayanan, Appl. Catal., A, 2002, 226, 175-182.

2 T. S. Jiang, Q. Zhao, M. Li and H. B. Yin, J. Hazard. Mater., 2008, 159, 204-209.

3 S. Zheng, M. Kates, M. A. Dubé and D. D. McLean, Biomass Bioenergy, 2006, 30, 267-272.

4 D. E. López, K. Suwannakarn, D. A. Bruce and J. G. Goodwin, J. Catal., 2007, 247, 43-50.

5 J. Gangadwala, S. Mankar and S. Mahajani, Ind. Eng. Chem. Res., 2003, 42, 2146-2155.

6 M. Mazzotti, B. Neri, D. Gelosa, A. Kruglov and M. Morbidelli, Ind. Eng. Chem. Res., 1997, 36, 3-10.

7 M. Petkovic, K. R. Seddon, L. P. N. Rebelo and C. S. Pereira, Chem. Soc. Rev., 2011, 40, 1383-1403.

8 N. V. Plechkova and K. R. Seddon, Chem. Soc. Rev., 2008, 37, 123-150.

9 T. Welton, Coord. Chem. Rev., 2004, 248, 2459-2477.

10 J. Dupont, R. F. Souza and P. A. Z. Suarez, Chem. Rev., 2002, 102, 3667-3692.

11 K. Qiao and Y. Q. Deng, J. Mol. Catal. A: Chem., 2001, 171, 8184.

12 J. Lunagariya, A. Dhar and R. L. Vekariya, RSC Adv., 2017, 7, 5412-5420.

13 X. Y. Jiang, W. D. Ye, X. H. Song, W. X. Ma, X. J. Lao and R. P. Shen, Int. J. Mol. Sci., 2011, 12, 7438-7444.

14 X. Z. Liang and C. Z. Qi, Catal. Commun., 2011, 12, 808-812.

15 K. P. Boroujeni and P. Ghasemi, Catal. Commun., 2013, 37, 50-54.

16 N. Azizi, M. A. Senejani and F. Abbasi, Tetrahedron Lett., 2016, 57, 5009-5011.
17 Y. H. Deng, F. Shi, J. J. Beng and K. Qiao, J. Mol. Catal. A: Chem., 2001, 165, 33-36.

18 J. Z. Gui, X. H. Gong, D. Liu, X. T. Zhang, Z. D. Hu and Z. L. Sun, Catal. Commun., 2004, 5, 473-477.

19 C. V. Doorslaer, J. Wahlen, P. Mertens, K. Binnemans and D. D. Vos, Dalton Trans., 2010, 39, 8377-8390.

20 H. Li, P. S. Bhadury, B. A. Song and S. Yang, RSC Adv., 2012, 2, 12525-12551.

21 A. Riisager, R. Fehrmann, M. Haumann and P. Wasserscheid, Top. Catal., 2006, 40, 91-102.

22 C. Y. Yuan, Z. W. Huang and J. Chen, Catal. Commun., 2012, 24, 56-60.

23 J. S. Beck, J. C. Vartuli, W. J. Roth, M. E. Leonowicz, C. T. Kresge, K. D. Schmitt, C. T.-W. Chu, D. H. Olson, E. W. Sheppard, S. B. McCullen, J. B. Higgins and J. L. Schlenkert, J. Am. Chem. Soc., 1992, 114, 10834-10843.

24 M. Kruk, M. Jaroniec, C. H. Ko and R. Ryoo, Chem. Mater., 2000, 12, 1961-1968.

25 Q. Zhao, X. P. Zhou, M. R. Ji, D. L. Wu, T. S. Jiang and H. B. Yin, Colloids Surf., A, 2011, 384, 513-518.

26 S. Kaiprommarat, S. Kongparakul, P. Reubroycharoen, G. Q. Guan and C. Samart, Fuel, 2016, 174, 189-196.

27 V. N. Mutlu and S. Yilmaz, Appl. Catal., A, 2016, 522, 194200.

28 S. Y. Chen, L. Y. Jang and S. Cheng, Chem. Mater., 2004, 16, 4174-4180.

29 W. L. Chu, X. G. Yang, X. K. Ye and Y. Wu, Appl. Catal., A, 1996, 145, 125-140.

30 H. T. R. Teo and B. Saha, J. Catal., 2004, 228, 174-182.

31 D. Y. Zhao, J. Y. Sun, Q. Z. Li and G. D. Stucky, Chem. Mater., 2000, 12, 275-279.

32 S. Y. Chen, J. F. Lee and S. F. Cheng, J. Catal., 2010, 270, 196205.

33 B. Zhou, D. H. Yu, J. J. Xia, S. S. Tang, W. M. Liu and H. Huang, Biochem. Eng. J., 2010, 53, 150-153.

34 Y. C. Du, S. Liu, Y. L. Zhang, F. Nawaz, Y. Y. Ji and F. S. Xiao, Microporous Mesoporous Mater., 2009, 121, 185-193.

35 C. Cai, H. Wang and J. Y. Han, Appl. Surf. Sci., 2011, 257, 9802-9808.

36 L. Zhang, Y. D. Cui, C. P. Zhang, L. Wang, H. Wan and G. F. Guan, Ind. Eng. Chem. Res., 2012, 51, 16590-16596.

37 D. J. Jones, J. J. Jiménez, A. J. López, P. M. Torres, P. O. Pastor, E. R. Castellónb and J. Rozière, Chem. Commun., 1997, 431-432.

38 J. C. Klein and D. M. Hercules, J. Catal., 1983, 82, 424-441. 39 Y. L. Yang, X. H. Wang and Y. Kou, Chem. Commun., 2004, 226-227.

40 J. Z. Gui, X. H. Cong, D. Liu, X. T. Zhang, Z. D. Hu and Z. L. Sun, Catal. Commun., 2004, 5, 473-477. 